\title{
Investigation of Hybrid Laminar Flow Control (HLFC) on a 2D-Model in the Cryogenic Pilot European Transonic Windtunnel (PETW)
}

\author{
Ann-Katrin Hensch ${ }^{1}$, Peter Guntermann ${ }^{2}$, Roberto Longo ${ }^{3}$, Jürgen Quest ${ }^{4}$, Patrick Okfen ${ }^{5}$, \\ European Transonic Windtunnel (ETW), D-51147 Cologne, Germany \\ Steffen Risius ${ }^{6}$, Christian Klein ${ }^{7}$, \\ German Aerospace Center (DLR), D-37073 Göttingen, Germany \\ Vladimir Ondrus ${ }^{8}$, Uwe Beifuss ${ }^{9}$, \\ University of Hohenheim, D-70599 Stuttgart, Germany \\ Sven Schaber ${ }^{10}$, \\ Airbus Operations, D-28199 Bremen, Germany
}

The application of Hybrid Laminar Flow Control (HLFC) by suction of the boundary layer has the potential to delay the location of laminar-turbulent transition and, hence, reduce drag caused by skin friction. Up to now most of the research on HLFC has been performed at low Reynolds and Mach numbers. To investigate the technology at flow conditions relevant for today's commercial flight additional studies at higher Reynolds numbers are required. At high Reynolds numbers the major challenge is an appropriate scaling of the perforation used for sucking the boundary layer, leading to very small perforation diameters of only a few microns.

In this paper, the applicability of HLFC on a two-dimensional wind tunnel profile is investigated in the cryogenic Pilot European Transonic Windtunnel (PETW). The natural laminar-turbulent boundary-layer transition is visualized with temperature-sensitive paint (TSP). The transition location obtained with an active HLFC system is compared to a reference case without HLFC for different angles of attack, Reynolds numbers, free stream Mach numbers and suction rates. Furthermore, the influence of the perforation diameter is also investigated. Results of an alternative approach, using a sintered porous material instead of a regular perforation for sucking the boundary layer, are also presented.

\footnotetext{
Research Project Engineer, akh@etw.de

Manager Operations \& Administration, pg@etw.de

Test Engineer, rlo@etw.de

Chief Aerodynamicist \& External Project Manager (retired), jq@etw.de, AIAA Associate Fellow

Student Aerospace at FH Aachen, patrick-marcello.okfen@alumni.fh-aachen.de

Research Scientist, Institute of Aerodynamics and Flow Techn., steffen.risius@dlr.de,

Research Scientist, Institute of Aerodynamics and Flow Techn., christian.klein@dlr.de, AIAA Associate Fellow

Research Scientist, Institute of Bioorganic Chemistry, vondrus@yahoo.com

Professor, Institute of Bioorganic Chemistry, ubeifuss@ uni-hohenheim.de

Research Scientist, Wind Tunnel Technology Development, sven.schaber@airbus.com
} 


\section{Nomenclature}

$\begin{array}{lll}\alpha & \text { angle of attack } & {\left[{ }^{\circ}\right]} \\ c & \text { chord length } & {[\mathrm{mm}]} \\ C Q & \text { suction coefficient } & {[-]} \\ M a & \text { Mach number } & {[-]} \\ N & \text { N-factor } & {[-]} \\ R a & \text { arithmetic mean roughness } & {[\mu \mathrm{m}]} \\ \operatorname{Re} & \text { Reynolds number } & {[-]} \\ x / c & \text { relative length } & {[-]}\end{array}$

\section{Introduction}

The application of Hybrid Laminar Flow Control (HLFC) by suction of the boundary layer provides the capability to reduce drag caused by skin friction and consequentially reduces fuel consumption of aircrafts. HLFC systems have been integrated in real aircraft and proven their capability for more than 20 years [1].

The integration of HLFC systems into wind tunnel models offers the potential to determine aircraft-drag reduction already at an early design state. To investigate HLFC systems at high Reynolds numbers experimentally it is required to develop appropriate systems for cryogenic wind tunnels, which allow the systematic variation of flow parameters such as the angle of attack, Reynolds number, Mach number and suction rate. Nowadays, new materials and treatments promise a breakthrough in the manufacturing of HLFC systems for high Reynolds number wind tunnel models [2], [3].

\section{Experimental investigations in the Pilot European Transonic Windtunnel (PETW)}

All experimental investigations were carried out in the Pilot European Transonic Windtunnel (PETW) under cryogenic conditions. The PETW is a closed circuit wind tunnel and can be operated at Mach numbers from $\mathrm{Ma}=0.15$ to 1.35 . Most investigations in this test were performed at a Mach number of $\mathrm{Ma}=0.24$.

To achieve high Reynolds numbers PETW is operated with nitrogen as a test gas, which makes it possible to lower tunnel-circuit temperatures down to $110 \mathrm{~K}$. Simultaneously, the pressure in PETW can be increased up to $400 \mathrm{kPa}$, allowing an independent adjustment of Mach and Reynolds numbers within certain limits. The chord Reynolds number in this test was varied from $\operatorname{Re}=1.6 \times 10^{6}$ to $\mathrm{Re}=7 \times 10^{6}$.

The 2D-model was installed horizontally inside the test section of PETW. The angle of attack of the model can be remotely controlled during tunnel operation and measured with an accuracy of $\pm 0.01^{\circ}$. The angle of attack was varied from $-2^{\circ}$ to $+2^{\circ}$ in this test.

To determine suction rates of the HLFC system the mass flow was measured and controlled during wind tunnel operation by a mass flow meter allowing variations between $0.0 \mathrm{~kg} / \mathrm{s}$ and $0.0011 \mathrm{~kg} / \mathrm{s}$. The measured mass flow was then combined with the measured temperature and pressure to derive a dimensionless suction coefficient $\mathrm{CQ}$, which is the ratio of suction velocity to freestream velocity.

To detect locations of laminar to turbulent transition with Temperature Sensitive Paint (TSP) a 12 bit CCD camera and an LED system were installed in the ceiling of the test section. TSP image acquisition was performed in this test with a frequency of $1 \mathrm{~Hz}$. For each test condition 40 images were acquired. The first 10 images were acquired at a constant flow temperature and averaged to provide a "reference image". Subsequently, the "run images" were taken during a temperature step leading to a heat transfer from the model surface to the flow or vice versa to enable transition to be visualized [4]. 


\section{The wind tunnel model for HLFC testing}

The experiments were performed using a two-dimensional wind tunnel model, designed for PETW in the framework of the European research project TELFONA [5]. The model has a chord length of $100 \mathrm{~mm}$ and features a blunt trailing edge. Three spanwise distributed suction chambers are integrated in the profile, ranging from $16 \%$ to $23 \%$ chord as shown in Figure 1. The design of these chambers foresees the integration of an insert into the profile above the suction chambers (red). The suction area has a width of $43 \%$ airfoil span and is situated on the right side of the model. The shape of the model was designed by DLR on the one hand for monitoring the transition over a wide range of Reynolds numbers and angles of attack downstream of the suction area and on the other hand to provide a large cross-section close to the leading edge to ensure sufficient space for the implementation of the suction chambers. A cross section through the model can be seen in Figure 2.

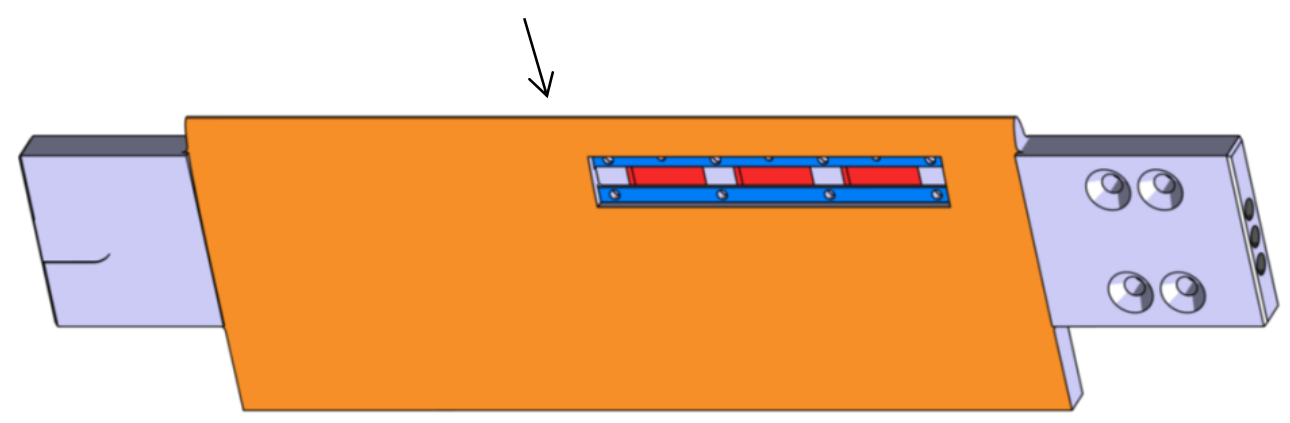

Figure 1: Two-dimensional model with suction chambers on the right side. Flat support tongues on each side are used to integrate the 2D-Model in the test section. The leading edge is on the upper side of the image.

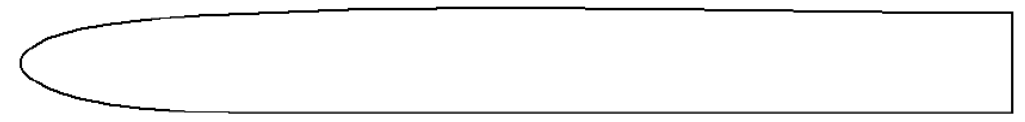

Figure 2: Cross section of the model featuring a slightly shaped upper surface with an elliptical leading edge [6].

\section{The suction system for HLFC}

The HLFC suction chambers were tubed across the wind tunnel model and the wind tunnel plenum and referenced to the free atmosphere in the wind tunnel building. The tunnel has always been operated at pressure levels ensuring overpressure above the suction area. The complete HLFC system consisted of a perforated insert, a mass flow controller and a perforated TSP coated foil (see sketch in Figure 3).

The perforated coated foil was glued to the surface of the 2D-model and the perforation extended over the insert. Perforated foils with different perforation diameters of $8 \mu \mathrm{m}, 20 \mu \mathrm{m}$ and $50 \mu \mathrm{m}$ were manufactured and applied to the wind tunnel model to allow suction of the boundary layer by the HLFC system. Therefore, the influence of hole diameters on transition and critical limits could be investigated.

The area below the perforation is connected to a mass flow controller to adjust the suction rate. The perforated insert fulfills two requirements: firstly, it allows the suction flow to pass from the upper surface through the model and secondly, it acts simultaneously as a support structure to prevent deformation of the stainless steel foil. To allow a sufficiently high flow rate and to prevent the TSP coated foil from distortion the insert featured 6000 support pillars. Below the support pillars 150 connection holes were machined into the ceiling of the suction chamber located below. To prevent temperature driven distortion effects due to different thermal expansion coefficients the insert and the wind tunnel model were made of the same material. 


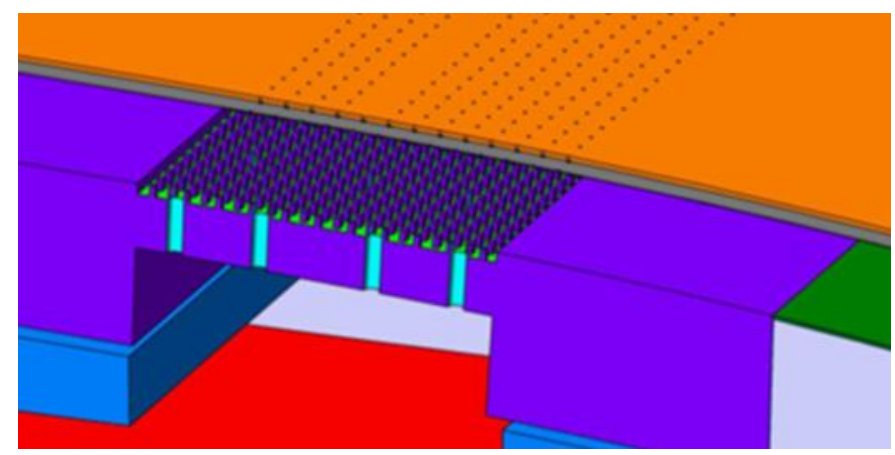

Figure 3: Schematic view of the suction system. From top to bottom: perforated stainless steel foil coated with TSP (orange), perforation insert with 6000 support pillars and 150 connection holes (blue), suction chamber.

A photo of the assembled model is shown in Figure 4. After carefully polishing the TSP coated surface a surface roughness of $\mathrm{Ra}<0.1 \mu \mathrm{m}$ was achieved, which is sufficiently low for high Reynolds number tests.

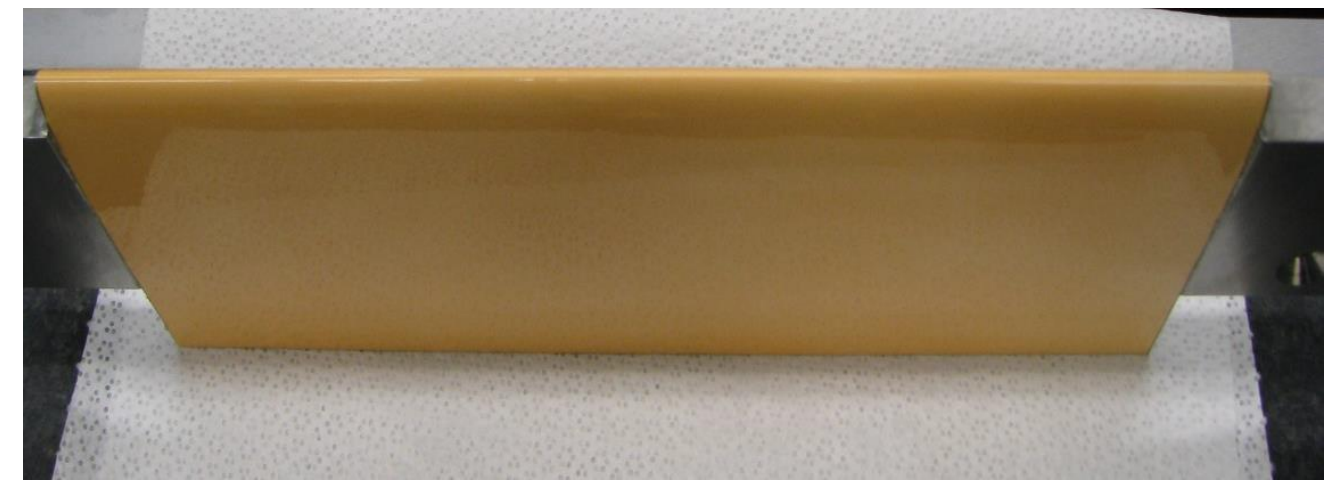

Figure 4: 2D wind tunnel model with TSP coated perforated foil applied to the surface.

\section{Data analysis and experimental method}

The following data analysis is based on the transition location assessed from TSP images. Surface pressure distributions were calculated based on the flow conditions and geometry of the wind tunnel model. Additionally, linear stability calculations were performed to allow theoretical predictions of the transition locations, used for comparison with the experimental results.

The dominant parameter in this experimental investigation is the hole diameter of the perforated TSP coated foils. A change of the hole diameter requires a removal and replacement of the complete perforated foils. For each model set-up a series of test points with varying Reynolds number and angles of attack (to vary the pressure gradient) have been selected. Then, the suction rate was step-wise increased to provide a raising amount of suction for removing the boundary layer. 


\section{Results of the perforated HLFC suction system}

It was found that an increasing suction rate first leads to a transition delay downstream, resulting in larger areas of laminar flow. However, at a certain suction rate the transition location starts to move upstream again, due to the increased suction. The maximum suction rate depends on the individual boundary layer stability.

As an example, Figure 5 outlines the result of a test case for an increase in suction rate expressed by the CQ-value. These results are obtained with a suction hole diameter of $8 \mu \mathrm{m}$. The transition line, theoretically a straight spanwise line due to the pure Tollmien-Schlichting caused origin, moves downstream relative to the most left image presenting the natural transition case. Figure 5 also visualizes the effect of a disturbance located in the suction area which results in the formation of a turbulent wedge as seen on the three rightmost images.

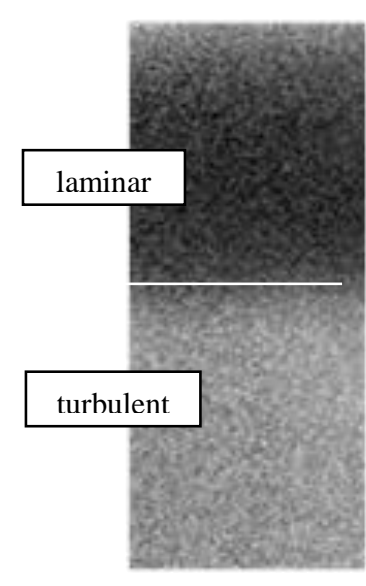

a)

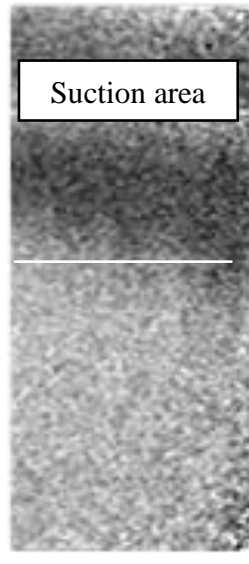

b)

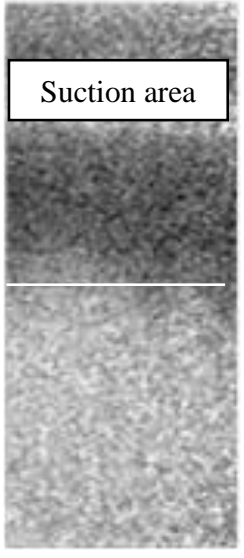

c)

d)

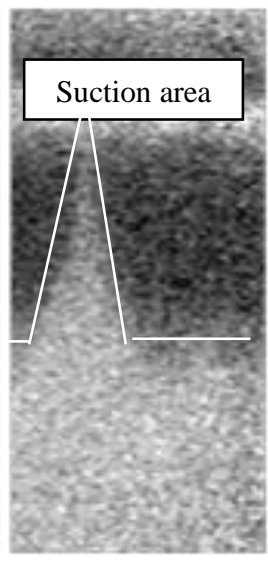

e)
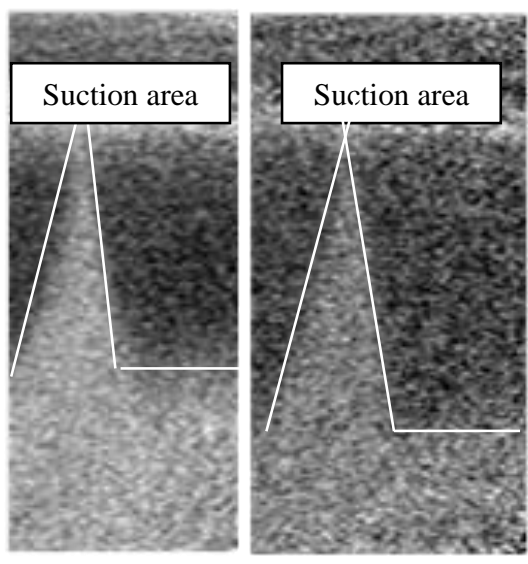

f)

Figure 5: Natural transition with zero suction (left) and transition location at variable suction levels with $\mathrm{CQ}=0.2 \times 10^{-3}, 0.4 \times 10^{-3}, 0.8 \times 10^{-3}, 1.2 \times 10^{-3}, 1.6 \times 10^{-3}$ for chord Reynolds number of $3 \times 10^{6}, \mathrm{Ma}=0.24$ and angle of attack $-0.5^{\circ}$.

Table 1 shows the transition location in $\mathrm{X} / \mathrm{C}$ in [\%] for the images shown in Figure 5. The natural transition takes place at $49 \%$ chord for the given flow and model parameters. When increasing suction the transition moves further downstream in relation to the amount of suction rate applied. Transition was shifted to $73 \%$ chord for the highest suction rate of $\mathrm{CQ}=1.6 \times 10^{-3}$.

\begin{tabular}{|c|c|c|c|}
\hline \multirow{2}{*}{ Transition } & \multirow{2}{*}{ Figure } & Suction Coefficient & Transition Location \\
\cline { 2 - 4 } & & $\mathrm{CQ}[-]$ & $\mathrm{X} / \mathrm{C}[\%]$ \\
\hline Natural transition & $5 \mathrm{a}$ & 0 & 49 \\
\hline \multirow{3}{*}{$\begin{array}{c}\text { Transition behind } \\
\text { suction area }\end{array}$} & $5 \mathrm{~b}$ & $0.2 \times 10^{-3}$ & 47 \\
\cline { 2 - 4 } & $5 \mathrm{c}$ & $0.4 \times 10^{-3}$ & 52 \\
\cline { 2 - 4 } & $5 \mathrm{~d}$ & $0.8 \times 10^{-3}$ & 60 \\
\cline { 2 - 4 } & $5 \mathrm{e}$ & $1.2 \times 10^{-3}$ & 67 \\
\cline { 2 - 4 } & $5 \mathrm{f}$ & $1.6 \times 10^{-3}$ & 73 \\
\hline
\end{tabular}

Table 1: Variation of transition location with suction coefficients for transition images shown in Figure 5. 
The behavior of transition as a function of suction rate is also investigated at higher Reynolds numbers. Figure 6 shows the results obtained at a chord Reynolds number of $5 \times 10^{6}$. Increasing the suction rate, represented by the CQ-value, also leads to a downstream shift of transition at this Reynolds number. Again, this figure also indicates two turbulent wedges, most likely caused by an impact of dust particles on the surface or a slight local imperfection of the coating.
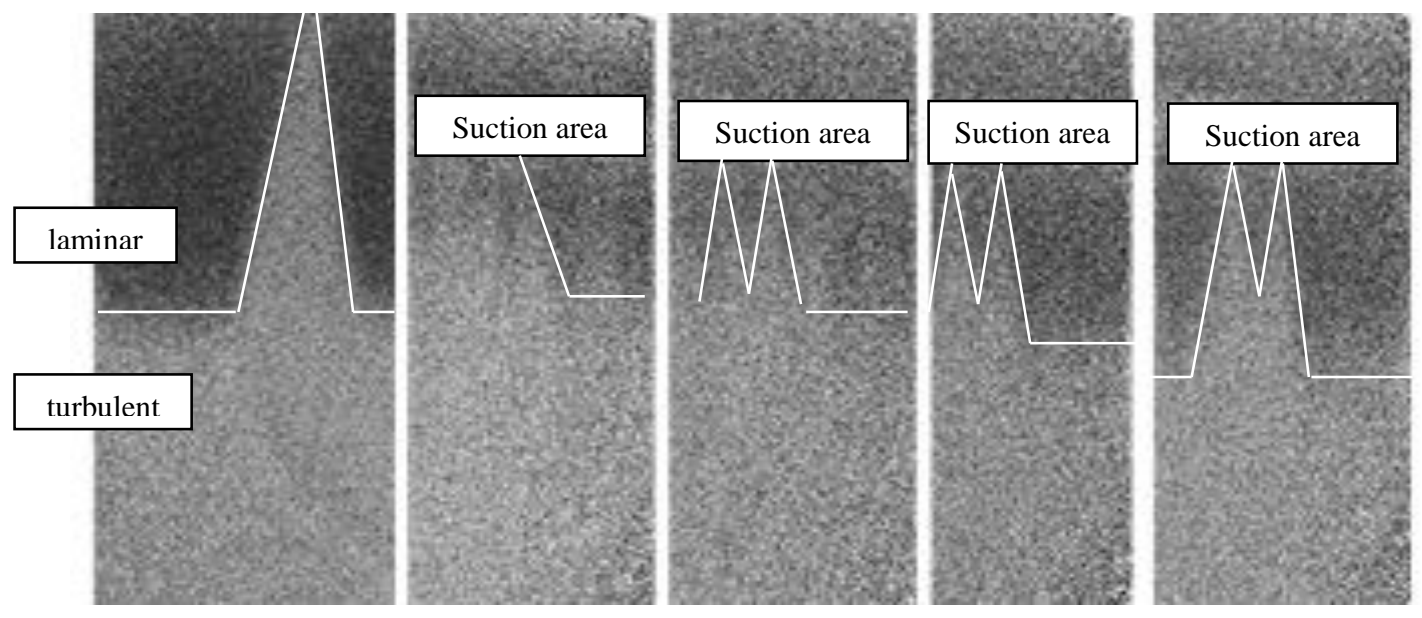

Figure 6: Natural transition with zero suction (left) and transition location at variable suction levels with $\mathrm{CQ}=0.4 \times 10^{-3}, 0.6 \times 10^{-3}, 0.8 \times 10^{-3}, 1.0 \times 10^{-3}$ for chord Reynolds number of $5 \times 10^{6}$, Ma $=0.24$ and angle of attack of $-1.5^{\circ}$.

The influence of different perforation diameters without suction is shown in Figure 7 and compared to the natural transition location without perforations shown in Figure 7a. It was found that an increase in suction hole diameter leads to an increasing disturbance of the boundary layer in the suction area. Whilst at a perforation diameter of $8 \mu \mathrm{m}$ the transition location behind the suction area is nearly identical with the transition location of the undisturbed flow, an increased hole diameter of $20 \mu \mathrm{m}$ or $50 \mu \mathrm{m}$ leads to a reduced laminarity compared to the undisturbed case.

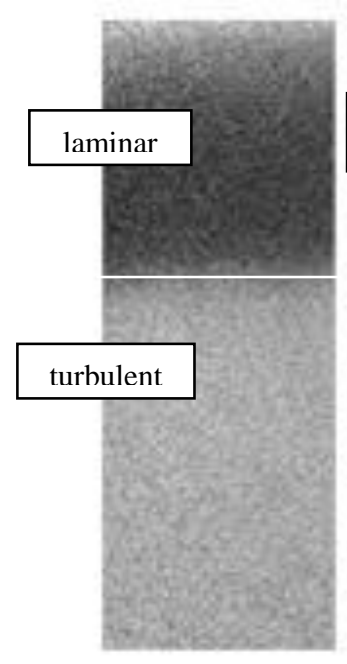

a)

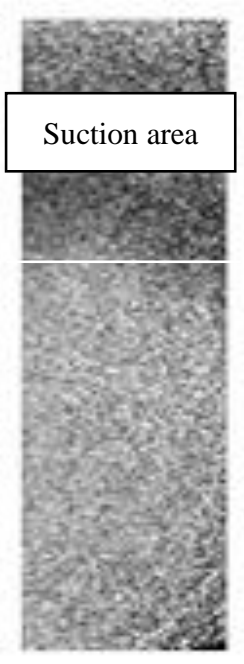

b)

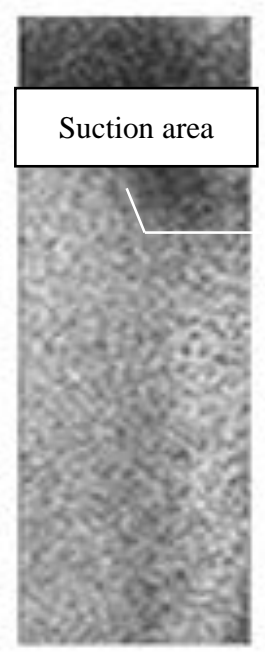

c)

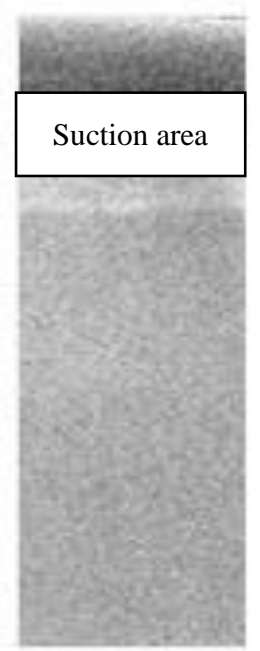

d)

Figure 7 Natural undisturbed transition (a) and transition location for different perforation diameters with zero suction $(8 \mu \mathrm{m}(\mathrm{b}), 20 \mu \mathrm{m}(\mathrm{c}), 50 \mu \mathrm{m}(\mathrm{d}))$ for a chord Reynolds number of $3 \times 10^{6}$, at a suction level of $\mathrm{CQ}=0, \mathrm{Ma}=0.24$ and angle of attack of $-0.5^{\circ}$ (Note: The Figure displays different signal-to-noise ratios due to different LED systems used for illumination). 
The comparison shown in Figure 7 is also presented for a constant suction coefficient of $\mathrm{CQ}=1.6 \times 10^{-3}$ and a chordwise Reynolds number of $1.6 \times 10^{6}$ in Figure 8. The same trend as shown in Figure 7 can also be observed in Figure 8 when suction is applied. The transition location behind the suction area is delayed by suction at small perforation hole diameters, whilst at the largest diameter of $50 \mu \mathrm{m}$ no delay can be observed. In general a relationship between the transition delay and the suction hole diameter can be found. For both cases with and without suction the location where the transition takes place downstream of the suction area is dependent on the perforation layout.

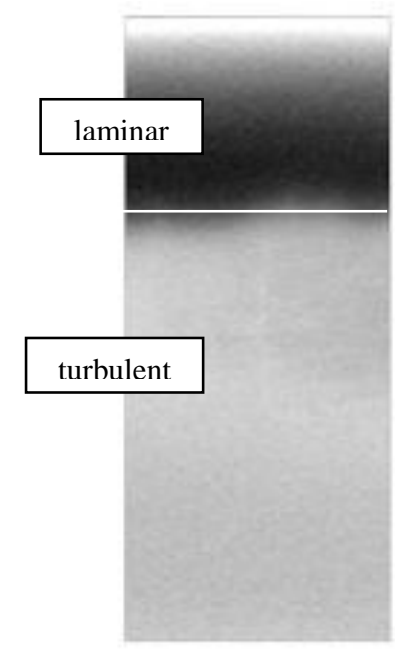

a)

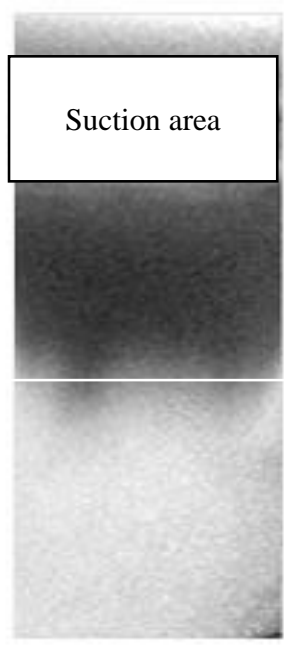

b)

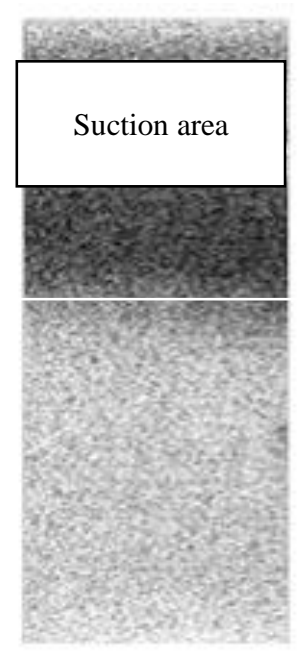

c)

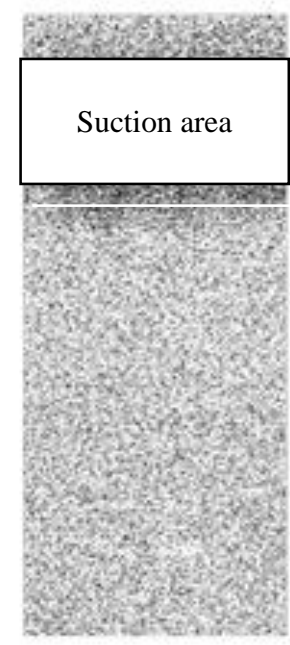

d)

Figure 8 Natural undisturbed transition with zero suction (a) and transition location at different perforation diameter $(8 \mu \mathrm{m}(\mathrm{b}), 20 \mu \mathrm{m}(\mathrm{c}), 50 \mu \mathrm{m}(\mathrm{d}))$ for chord Reynolds number of $1.6 \times 10^{6}$, at a suction level of $\mathrm{CQ}=1.6 \times 10^{-3}$, $\mathrm{Ma}=0.24$ and angle of attack of $+1^{\circ}$ (Note: The Figure displays different signal-tonoise ratios due to different LED systems used for illumination).

As a preparation for the wind tunnel measurements, stability calculations by using the boundary layer code COCO [7] in combination with the linear stability equations solver LILO [8] were performed for a set of flow parameters. These results formed the basis for the definition of flow parameters and model incidences to be tested in PETW. A comparison of the measured and calculated Tollmien-Schlichting instability based natural transition locations is given in Figure 9 as a function of the angle of attack. The achieved agreement between the measured and calculated natural transition location is considered to be satisfactory for the current scope of testing. While Figure 9 shows the comparison of two measurement points for a Reynolds number of $7 \times 10^{6}$, an even better agreement was found for smaller Reynolds numbers.

Additionally, stability calculations have been performed for different suction coefficients, Reynolds numbers and model incidences. As an example, Figure 10 shows the calculated transition location for a Reynolds number of $3 \times 10^{6}$ and a model incidence of $0.5^{\circ}$. In Figure 10 the calculated transition locations can be compared to the measured transition locations in PETW for different suction coefficients. A good agreement between the calculated and measured transition locations was found. 


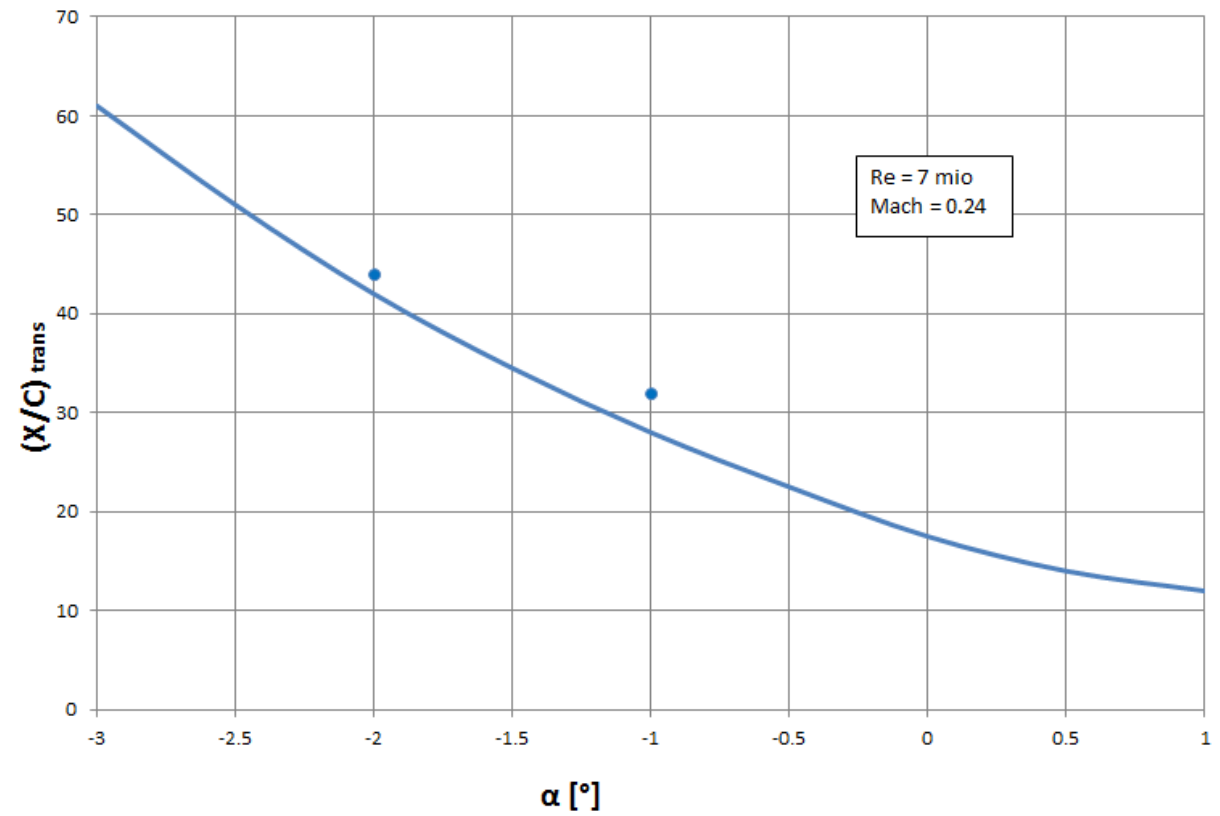

Figure 9: Transition location, $x / c$, for various angles of attack and a chord Reynolds number of $R e=7 \times 10^{6}$ at $\mathrm{Ma}=0.24$. Natural transition locations measured (dots) and predicted (line) by linear stability theory at $\mathrm{N}=10$ are shown.

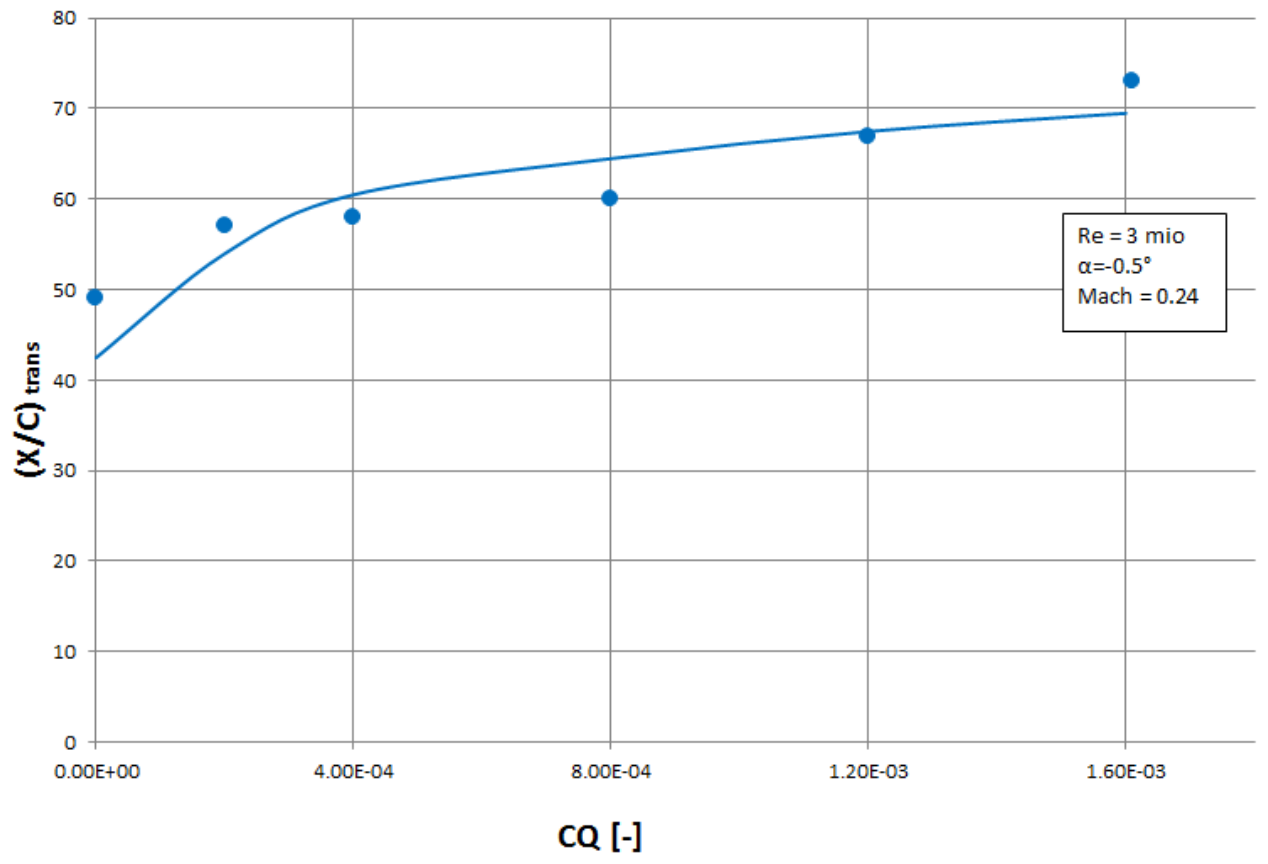

Figure 10: Transition locations $x / c$, for various suction coefficients $C Q$ and a chord Reynolds number of $\mathrm{Re}=3 \times 10^{6}$, an angle of attack of $-0.5^{\circ}$ with $\mathrm{Ma}=0.24$. Natural transition locations measured (dots) and predicted (line) by linear stability theory at $\mathrm{N}=10$ are shown. 


\section{Results of an alternative approach with a sintered material HLFC suction system}

An alternative approach with a porous sintered material [6] used for suction of the boundary layer was also investigated within the European research project TELFONA. The first experiments on sucking the boundary layer on a scaled model at cryogenic conditions confirmed a general feasibility of the selected concept. However, the porous sintered material used for suction could not be qualified for tests at the cryogenic temperatures required to achieve the highest Reynolds numbers.

Figure 11 shows an example of transition visualization by TSP. Figure 11a shows a reference transition result without any HLFC suction device, whilst Figures $11 \mathrm{~b}$ and $11 \mathrm{c}$ show the transition location downstream of the porous sintered material for a chord Reynolds number of $1.6 \times 10^{6}$ and an angle of attack of $+1.2^{\circ}$. In Figure 11b no suction is applied leading to laminar-turbulent transition directly downstream of the porous sintered material. When suction is applied, as shown in Figure 11c, it is possible to compensate the distortion of the boundary layer leading to a significant shift downstream of the transition. This observation may be attributed to the increased surface roughness of the sintered material or steps and gaps between the perforated insert and the wind tunnel model. At higher Reynolds numbers distortions generated by the perforated insert could not be compensated anymore by applying suction. Therefore this approach using a sintered material was not investigated further.

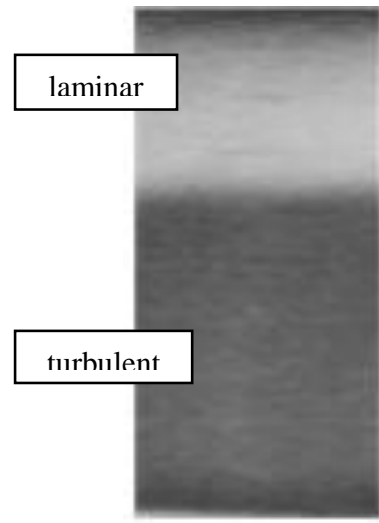

a)

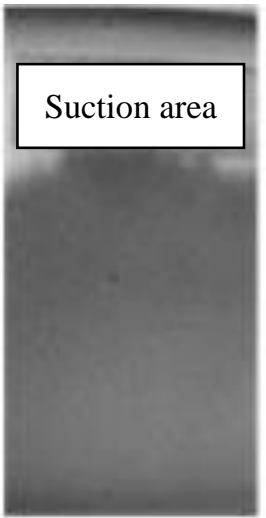

b)

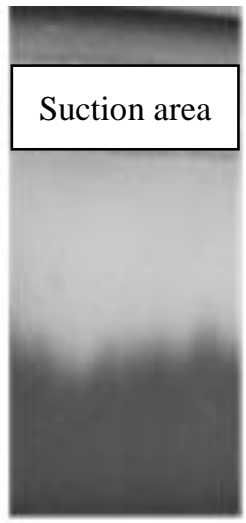

c)

Figure 11: Transition location for $C Q=0(a, b)$ and $C Q=2.01 \times 10^{-3}(c)$ at $\operatorname{Re}=1.6 \times 10^{6}$ and $\alpha=1.2^{\circ}$

\section{Conclusion}

Two different approaches for the realization of a Hybrid Laminar Flow Control (HLFC) system in a cryogenic wind tunnel were developed and tested. It was found that an approach using a sintered material was not suited to investigate HLFC systems at large Reynolds numbers. However, a different approach, using a perforated foil, showed promising results to investigate HLFC systems also at high Reynolds numbers within a cryogenic environment. For flows featuring Tollmien-Schlichting instabilities it was shown that the hole diameter of the suction system has to be sufficiently small to achieve a laminar flow length comparable to an undisturbed flow (without HLFC surface). Furthermore, it was found that the location of laminar-turbulent transition can be delayed by suction of the boundary layer at cryogenic conditions. It could be experimentally confirmed that suction above a certain rate starts moving the transition location upstream again. The experimentally achieved results show good agreement with predictions by linear stability calculations. 


\section{Acknowledgements}

The authors would like to thank Thomas Baumgart (ETW) for his dedicated support during the model preparation and TSP surface finishing. Furthermore, we would like to thank the PETW wind tunnel crew for their helpful support during the test setup and the measurements. Special thanks go to the people working at the organization Fraunhofer UMSICHT and Deharde Maschinenbau with respect to performing the perforation of the suction foils and the manufacturing of the foil substructure. The authors are grateful for the project funding by the German Federal Ministry for Economic Affairs and Energy (LuFo-V-2 ReSK, FKZ 20A1503A).

\section{References}

[1] Joslin R. D., Overview of laminar flow control, NASA/TP-1998-208705, 1998.

[2] Föhl C., Laser in der Materialbearbeitung, Einsatz ultrakurz gepulster Laserstrahlung zum Präzisionsbohren von Metallen, Herbert Utz Verlag GmbH, 2011.

[3] Gehrke I., Metallische Mikrosiebe -mikrotechnische Herstellung und filtertechnische Charakterisierung-, Dissertation, Bochum 2007.

[4] Fey U. and Egami Y., Transition Detection by Temperature-Sensitive Paint, Springer Handbook of Experimental Fluid Mechanics. Chapter. 7.4, Springer Verlag, Berlin Heidelberg, 2007.

[5] Horstmann K. H., TELFONA, Contribution to Laminar Wing Development for Future Transport Aircraft, Aeronautical Days, Vienna, 2006.

[6] Deters C., Quest J., Test report TELFONA Task 3.1-7, Experimental verification of a HLFC concept for high Reynolds number simulation, Cologne, 2009 [Project confidential].

[7] Schrauf G., COCO User Manual: a program to compute velocity and temperature profiles for local and nonlocal stability analysis of compressible, conical boundary layers with suction, ZARM Technik Report, Airbus, Bremen, 1998.

[8] Schrauf G., LILO 2.1 User's guide and tutorial, GSSC Technical Report 6, Airbus, Bremen, 2006. 